J. Dairy Sci. 92:35-48

doi:10.3168/jds.2008-1263

(c) American Dairy Science Association, 2009.

\title{
Glycosylation and expanded utility of a modified whey protein ingredient via carbohydrate conjugation at low $\mathrm{pH}^{1,2}$
}

\author{
J. S. Lillard, D. A. Clare, and C. R. Daubert ${ }^{3}$ \\ Department of Food, Bioprocessing, and Nutrition Sciences, North Carolina State University, Raleigh 27695
}

\begin{abstract}
Whey protein, at one time considered a by-product of the cheese-making process, is now commonly used in foods for its thickening and emulsifying properties. Currently, approximately $30 \%$ of these proteinaceous resources remain under-utilized. Previously, an acidified, thermally treated whey protein concentrate (mWPC) was developed to produce a cold-set thickening ingredient. Mass spectroscopy revealed an approximate 2.5fold decrease in the lactosylation of $\beta$-lactoglobulin in mWPC starting materials compared with commercial whey protein concentrates, manufactured at a higher $\mathrm{pH}$. Potentially, this should increase the number of reactive sites that remain available for carbohydrate attachment. With this study, the formation of glycoprotein complexes was demonstrated between the mWPC ingredient and lactose, naturally occurring in mWPC powders, or between mWPC protein components with dextran (35 to 45 and 100 to $200 \mathrm{kDa}$ ) materials at low $\mathrm{pH}$. In fact, additional dry heating of mWPC powders showed a 3 -fold increase in the amount of lactosylated $\beta$-lactoglobulin. Evidence of Maillard reactivity was suggested using colorimetry, o-phthaldialdehyde assays, and sodium dodecyl sulfate PAGE followed by glycoprotein staining. Resultant glycoprotein dispersions exhibited altered functionality, in which case steady shear and small amplitude oscillatory rheology parameters were shown to be dependent on the specific reducing sugar present. Furthermore, the emulsion stability of mWPC-dextran fractions was 2 to 3 times greater than either mWPC or commercial WPC dispersions based on creaming index values. The water-holding capacity of all test samples decreased with additional heating steps; however, mWPC-dextran powders still retained nearly 6 times their weight of water. Scanning electron
\end{abstract}

\footnotetext{
Received April 10, 2008.

Accepted September 9, 2008.

${ }^{1}$ Paper no. FSR-02-42 of the Journal Series of the Department of Food Science, North Carolina State University, Raleigh 27695-7624.

${ }^{2}$ The use of trade names in this publication does not imply endorsement by the North Carolina Agricultural Research Service of products named, or criticism of similar ones not mentioned.

${ }^{3}$ Corresponding author: chris_daubert@ncsu.edu
}

microscopy revealed that mWPC-dextran conjugates formed a porous network that differed significantly from the dense network observed with mWPC samples. This porosity likely affected both the rheological and waterbinding properties of mWPC-dextran complexes. Taken together, these results suggest that the functionality of $\mathrm{mWPC}$ ingredients can be enhanced by conjugation with carbohydrate materials at low $\mathrm{pH}$, especially with regard to improving the emulsifying attributes.

Key words: whey glycoprotein, lactosylation, Maillard reaction at low $\mathrm{pH}$, emulsion

\section{INTRODUCTION}

Whey proteins are commonly added to a variety of foods including dairy and meat products along with baked goods because of their high nutritional value and potential for improving functionality (DeWit, 1989). In general, dairy proteins often function in food systems to impart viscosity, bind water, provide a coating for some consumer goods, and improve emulsification or foaming characteristics (Morr, 1979, 1982; DeWit, 1984, 1989; Kinsella et al., 1989; Mishra et al., 2001). The demand for whey as well as the environmental and financial costs for whey disposal made it profitable for companies to convert a one-time waste stream into a marketable source of revenue. As of 2002, whey accounted for approximately $11 \%$ of the revenue generated by a modern cheese plant (Balagtas et al., 2003). In 2005, whey protein concentrate produced for human consumption reached approximately 325 million pounds (USDA, 2006). According to the report of Balagtas et al. (2003), at least $30 \%$ of whey protein products remain unused, leading developers to devise new ingredient opportunities.

As such, various modifications of these materials are often accomplished to increase potential function in foods. In 2001, Hudson and colleagues patented a method for modifying whey protein isolates (mWPI) that showed expanded functional characteristics over native whey (Hudson et al., 2001). This protocol involved lowering the $\mathrm{pH}$ of a whey protein solution to 3.35 , followed by heating at $80^{\circ} \mathrm{C}$ for $3 \mathrm{~h}$ to induce gelation. The gel was then frozen, lyophilized, and ground 
Table 1. Composition of the samples

\begin{tabular}{lcccc}
\hline Sample & mWPC $^{1}$ & Dextran 100 & Solids, $\%$ & Protein, \% (wt/vol) \\
\hline 1 & 1 part & 0 parts & 8 & 5.6 \\
2 & 2 parts & 1 part & 8 & 3.7 \\
3 & 3 parts & part & 8 & 4.2 \\
\hline
\end{tabular}

${ }^{1} \mathrm{mWPC}=$ modified whey protein concentrate.

to a fine powder. This modified whey protein displayed cold-set thickening functionality without requiring additional heat steps or salts. Further characterization work by Firebaugh (2004) showed improved emulsifying and foaming properties with respect to mWPI systems.

Often, enhanced whey functionality can be achieved through covalent linkage of whey proteins to carbohydrates via nonchemical means such as the Maillard reaction (Dickinson and Semenova, 1992; Dickinson and Izgi, 1996; Mishra et al., 2001; Akhtar and Dickinson, 2003; Einhorn-Stoll et al., 2005). This reaction occurs naturally during thermal processing in contrast to other methods of conjugation such as acetylation, deamidation, and succinylation (Oliver et al., 2006), all of which may cause significant changes to the performance characteristics of the final product.

The objectives of this study were to establish whether or not modified whey protein concentrate (mWPC)carbohydrate complexing reactions may be achieved at low $\mathrm{pH}$, and to evaluate the ensuing changes that occurred in the functionality of these products as a result of conjugation. Subsequently, characterization of hydration-based properties such as viscosity, gelation, and water-holding capacity, together with surface characteristics (e.g., emulsification) were assessed using multiple methodologies (Morr and Ha, 1993). Ultimately, such glycoprotein ingredients may prove useful for application in specific food products based on enhanced viscoelastic properties, as was observed in lactosylated mWPC dispersions, and improved emulsion stability attributed to mWPC-dextran complex formation.

\section{MATERIALS AND METHODS}

\section{Materials}

A commercial whey concentrate (cWPC, $78.1 \%$ protein, wt/wt) and a modified whey protein concentrate (mWPC; 70.4\% protein, wt/wt) powder, manufactured according to the method of Resch and Daubert (2002) with slight modification, was generously provided by Grande Custom Ingredients (Lomira, WI). The company also provided information for the moisture, ash, fat, and carbohydrate contents. Nitrogen analysis was performed by the Analytical Services Laboratory (NC State University, Raleigh, NC) using a CHN Elemental
Analyzer, Series II (Perkin Elmer Corp., Norwalk, CT), and protein content was calculated using the equation $\mathrm{N} \times 6.38$ (Onwulata et al., 2004).

Two dextran samples (35 to $45 \mathrm{kDa}$, DX35; and 100 to $200 \mathrm{kDa}, \mathbf{D X} 100)$ from Leuconostoc mesenteroides were purchased from Sigma-Aldrich (St. Louis, MO). A bicinchoninic acid (BCA) protein assay kit, o-phthaldialdehyde (OPA) assay reagent, and glycoprotein staining kit were obtained from Pierce (Rockford, IL), while precast Tricine SDS-polyacrylamide gradient gels (10 to $20 \%$ ) and a colloidal blue staining reagent were purchased from Invitrogen Life Technologies (Carlsbad, $\mathrm{CA})$.

\section{Sample Preparation}

Initially, an appropriate ratio of protein to carbohydrate was determined by dissolving stock solutions of mWPC powder and DX100 in deionized water at 3 protein:carbohydrate ratios (1:0, 2:1, and 3:1), such that all dispersions contained $8 \%$ solids. Detailed formulations are summarized in Table 1.

All test solutions were stirred at $150 \mathrm{rpm}$ for $2 \mathrm{~h}$, the $\mathrm{pH}$ adjusted to 3.5 with $6 \mathrm{~N} \mathrm{HCl}$, and lyophilized for $48 \mathrm{~h}$ using a 4.5-L bench-top freeze dryer (Labconco, Kansas City, MO). The resulting powder was ground to a fine particle size and heated in an Isotemp 630G convection oven (Fisher Scientific, Pittsburgh, PA) for $2 \mathrm{~h}$ at $100^{\circ} \mathrm{C}$ to form glycoconjugates. Each conjugate was prepared in duplicate and, in some cases, triplicate. All measurements were performed in triplicate.

\section{BCA Assay}

The BCA assay was used to determine the protein concentration according to established protocols developed by Pierce Inc. (Rockford, IL). Previously, Smith et al. (1985) found that reducing sugars may cause erroneous results when protein determinations were performed according to these methodologies; however, an evaluation of control dextran materials showed no evidence of interference under the current reaction conditions.

\section{Colorimetric Assay}

Reflectance measurements of dry powdered mWPC, mWPC-DX35, and mWPC-DX100 glycoconjugates 
were determined using a Konica Minolta CR-300 Chroma Meter (Tequipment, Long Branch, NJ) with diffuse illumination $/ 0^{\circ}$. The readings were made in triplicate and based on the Hunter $\mathrm{L}^{*}, \mathrm{a}^{*}, \mathrm{~b}^{*}$ scale, where $\mathrm{L}^{*}=$ lightness, $\mathrm{a}^{*}=$ redness, and $\mathrm{b}^{*}=$ yellowness (Hunter Lab, 1996).

\section{Ionization Mass Spectrometry}

A nonheated sample of mWPC and cWPC, as well as thermally processed mWPC samples were analyzed by the NC State University Metabolomics and Proteomics Laboratory using an ionization mass spectrometer to determine the degree of lactosylation between lactose and $\beta$-LG during heating. Dried samples $(50 \mu \mathrm{g})$ were reconstituted in $100 \mu \mathrm{L}$ of $10 \mathrm{~m} M$ dithiothreitol pre-

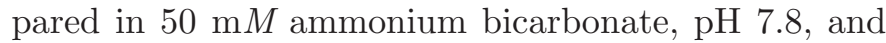
heated for $1 \mathrm{~h}$ at $56^{\circ} \mathrm{C}$. Upon cooling to room temperature, $100 \mu \mathrm{L}$ of $55 \mathrm{~m} M$ iodoacetamide, prepared in 50 $\mathrm{m} M$ ammonium bicarbonate, $\mathrm{pH} 7.8$, was added and held at room temperature for $45 \mathrm{~min}$. Sequencing-grade trypsin (1 $\mu \mathrm{g}$, Sigma Aldrich) was then added and the sample digested overnight at $37^{\circ} \mathrm{C}$.

Samples were analyzed with a Thermo LTQ linear ion trap mass spectrometer with Surveyor HPLC and autosampler (Thermo, San Jose, CA). Briefly, a 5- $\mu \mathrm{L}$ sample of the digest was injected onto a $150 \times 0.5 \mathrm{~mm}$ Jupiter Proteo C18 Phenomenex column (Torrance, CA), previously equilibrated in water:acetonitrile (97:3) containing $0.01 \%$ trifluoroacetic acid and $0.005 \%$ heptafluorobutyric acid. A linear gradient, 0 to $60 \%$ acetonitrile, was applied over $70 \mathrm{~min}$ to elute tryptic peptides. Data-dependent tandem mass spectrometry spectra were used to provide internal sequence identity of the eluting peptides. The MS/MS spectra were searched in Bioworks Browser 3.1 (Thermo), allowing for a dynamic modification of lysine residues $(+342$ amu) corresponding to lactosylation.

\section{OPA assay}

The OPA spectrophotometric assay method was based on the method of Church et al. (1983). Test samples were microcentrifuged (model 235C, Fisher Scientific) at $13,600 \times g$ for $10 \mathrm{~min}$ and the soluble protein in the supernatant diluted 1:10 with deionized water. Afterward, $50 \mu \mathrm{L}$ of the diluted solution was added to $2.0 \mathrm{~mL}$ of OPA reagent, incubated for $5 \mathrm{~min}$ at $25^{\circ} \mathrm{C}$, and absorbance readings made at $\mathrm{A}_{340 \mathrm{~nm}}$ using a Gilford Instrument 2600 UV-Visible spectrophotometer (Gilford, Oberlin, OH). The concentration $(\mu M)$ of reactive amino groups per milligram of protein was then calculated. All analyses were performed in triplicate.

\section{Sample Preparation for SDS-PAGE and Glycoprotein Staining}

Test samples were prepared using cWPC, mWPC, heated mWPC, mWPC-DX35, and mWPC-DX100 dried powders $\left(100^{\circ} \mathrm{C}, 2 \mathrm{~h}\right)$, and rehydrated to $5.6 \%$ protein in distilled, deionized water. The protein fraction, associated with heated dispersions, was precipitated using $70 \%$ ammonium sulfate, left overnight at $4^{\circ} \mathrm{C}$, and centrifuged at $17,210 \times \mathrm{g}$. The pellet fraction was resuspended and dialyzed against distilled water for $48 \mathrm{~h}$ at $4^{\circ} \mathrm{C}$. The samples were then used for electrophoresis and glycoprotein staining.

\section{SDS-PAGE}

Tricine 10 to $20 \%$ gradient polyacrylamide gels were used to evaluate protein and glycoprotein banding patterns. Bicinchoninic acid assays were performed to ensure that equivalent amounts of protein were loaded into each lane. Samples were mixed with 0.9 $M$ Tricine sample buffer containing $8 \%$ SDS and $5.0 \%$ $\beta$-mercaptoethanol, and then heated at $100^{\circ} \mathrm{C}$ for 10 min, before loading $20 \mu \mathrm{L}$ into the sample well. Electrophoresis was accomplished using a Novex Power Ease 500 Power Supply (Invitrogen Inc.) that was programmed to run for 85 min at $125 \mathrm{~V}$. After completion, gels were stained to visualize protein bands using a colloidal Coomassie Blue staining reagent (Invitrogen Inc.). Alternatively, glycoproteins were detected after development with a carbohydrate staining dye (GelCode Glycoprotein Staining Kit; Thermo Scientific, Rockford, IL).

\section{Steady Shear Rheological Analysis}

To evaluate the apparent viscosity $(\eta)$, experimental samples were hydrated in deionized water to a final concentration of $7 \%$ protein (wt/vol), stirred at 150 rpm for $2 \mathrm{~h}$, and the $\mathrm{pH}$ adjusted to 3.5. Test samples were presheared at $15 \mathrm{~s}^{-1}$ for $30 \mathrm{~s}$ and subsequent shear rate ramps $\left(0.1\right.$ to $\left.500 \mathrm{~s}^{-1}\right)$ conducted at $25^{\circ} \mathrm{C}$ with a StressTech Controlled Stress Rheometer (ReoLogica Instruments AB, Lund, Sweden) using a 25-mm serrated couette assembly.

\section{Small Amplitude Oscillatory Shear}

Viscoelastic properties were examined by small amplitude oscillatory shear. Heated and nonheated samples, containing $7 \%$ protein, were hydrated at a $2: 1$ ratio of protein to carbohydrate in deionized water. A StressTech Controlled Stress Rheometer (ReoLogica Instruments $\mathrm{AB}$ ) with a $25-\mathrm{mm}$ serrated couette as- 
sembly was used to perform both a stress sweep to establish the linear viscoelastic region and a frequency sweep to evaluate storage $\left(\mathbf{G}^{\prime}\right)$ and loss $\left(\mathbf{G}^{\prime \prime}\right)$ moduli. A determination of the linear viscoelastic region was achieved by maintaining a frequency of $10 \mathrm{~Hz}$ while the stress was increased from 0.01 to $50 \mathrm{~Pa}$. Using these data, the stress was then held constant at $1.0 \mathrm{~Pa}$ while the frequency was increased from 0.01 to $10 \mathrm{~Hz}$.

\section{Emulsion Stability}

Stock solutions were prepared at $5 \mathrm{mg} / \mathrm{mL}$ protein using mWPC, mWPC-DX35, or mWPC-DX100 powders, dispersed in deionized water, and the $\mathrm{pH}$ was adjusted to 3.5. A cWPC powder was also hydrated accordingly; however, the $\mathrm{pH}$ read 6.6. All solutions were stirred for $2 \mathrm{~h}$ at $150 \mathrm{rpm}$, and hydrated overnight at $4^{\circ} \mathrm{C}$; sodium azide added to $0.02 \%$ (wt/vol) to prevent microbial growth. Test fractions were prepared at a 1:1 ratio with corn oil and blended in a Waring blender for approximately $1 \mathrm{~min}$ at room temperature. The solutions were immediately homogenized in 2 passes using a Panda $2 \mathrm{~K}$ NS1001L homogenizer (GEA Niro Inc., Columbia, MD) at a setting of $200 \mathrm{MPa}$ on stage 1 to form an emulsion. The particle size for each sample was determined using a centrifugal particle size analyzer (SA-CP4, Shimadzu, Columbia, MD), ensuring that the droplet size was in the same range and approached the ideal size of $1 \mu \mathrm{m}$ (Genovese et al., 2007).

Emulsion stability was assessed based on an evaluation of the creaming index as described by Demetriades and McClements (1999). For these experiments, $10 \mathrm{~mL}$ of each emulsion was placed in a $15-\mathrm{mL}$ centrifuge tube and stored at ambient temperature for a period of $1 \mathrm{wk}$. During this period, each sample separated into 2 layers with a droplet-rich layer on top and droplet-depleted layer on the bottom. An example is illustrated in Figure 1. The total height of each emulsion (HE) and the height of the droplet depleted layer (HD) were measured in triplicate. The creaming index was reported as:

$$
\text { Creaming index }(\%)=100 \times\left(\frac{H D}{H E}\right) \text {. }
$$

\section{Scanning Electron Microscopy and Water-Holding Capacity}

All samples were placed in a $78-\mu \mathrm{m}$ microporous capsule (Structure Probe Inc., West Chester, PA), and immersed into $2 \mathrm{~mL}$ of cold $3 \%$ glutaraldehyde buffered with $0.1 M$ sodium acetate buffer, $\mathrm{pH} 3.5$, for $24 \mathrm{~h}$. The liquid whey sample formed a solid mass, which enabled sectioning into 2 - to $3-\mathrm{mm}^{3}$ pieces that were subsequently washed 2 to 3 times with buffer for 20 min at $4^{\circ} \mathrm{C}$. Dehydration steps were then performed using an ethanol series of $30,50,70,95$, and $100 \%$ for $20 \mathrm{~min}$ each at $4^{\circ} \mathrm{C}$. The samples were dried with a Samdri-795 critical point dryer (Tousimis, Rockville, $\mathrm{MD})$, sliced into $1-\mathrm{mm}^{3}$ pieces, and coated with gold/ palladium (25 to $30 \mathrm{~nm}$ ) using an Anatech Hummer 6.2 sputter coater (Anatech Ltd., Denver, NC) for imaging. The microscope used for the studies was a JEOL JSM5900LV model (Jeol, Tokyo, Japan) with an accelerating voltage of $20 \mathrm{kV}$.

The water-holding capacity was determined according to the method described by Resch and Daubert (2002).

\section{Statistical Analyses}

Data were analyzed using SAS software (version 9.1; SAS Institute, Inc., Cary, NC). Significant effects, based on the carbohydrate reactant and various thermal treatments, were evaluated by ANOVA with means separation (least squares means).

\section{RESULTS AND DISCUSSION}

Analyses of mWPC powders showed a relatively high protein content, approximately $70 \%$, with $13 \%$ carbohydrate (wt/wt). These values differed slightly from those measured in the cWPC fraction (Table 2). Because the mWPC ingredient already contained lactose, a major objective for this study was focused on characterizing the biochemical and rheological effects of protein:carbohydrate conjugation reactions between mWPC proteins with lactose compared with complex formation between mWPC and dextran materials, under dry heating conditions at low $\mathrm{pH}$. The following results highlight the observation that the degree of lactosylation significantly affected the viscoelasticity of heated mWPC dispersions, whereas glycosylation improved emulsion stability of mWPC-dextran solutions.

\section{Colorimetric Assay}

Hunter L*, $\mathrm{a}^{*}, \mathrm{~b}^{*}$ measurements, attributed to color development, are summarized in Table 3. Such tests have been used successfully to monitor color changes in food systems such that the highest complexing activity equates to $\mathrm{L}^{*}$ values approaching zero (Reyes et al., 1982; Nielson et al., 1997). The degree of color formation, from darkest to lightest, is represented in the following order: heated mWPC (lactose) > mWPC-DX100 $>$ mWPC-DX35 > mWPC-nonheated. Because these experimental samples were prepared on a per weight basis, the molar concentration of DX35 is actually 
Table 2. Analytical analyses of modified (mWPC) and commercial (cWPC) whey protein concentrates

\begin{tabular}{lccccc}
\hline Sample & Protein, ${ }^{1} \%$ & Moisture, $\%$ & Ash, $\%$ & Fat, $\%$ & Carbohydrate, $\%$ \\
\hline mWPC & 70.37 & 3.97 & 8.50 & 3.99 & 13.17 \\
cWPC & 78.09 & 4.56 & 2.70 & 4.81 & 9.84 \\
\hline
\end{tabular}

${ }^{1}$ Protein was determined by micro-Kjeldahl $(\mathrm{N} \times 6.38$; Onwulata et al., 2004); analyses of moisture, ash, fat, and carbohydrate were provided by Grande Custom Ingredients Group (Lomira, WI).

greater than that of dispersions prepared with DX100, reflecting an increased number of reducing sugar end groups. It was noted, however, that the mWPC-DX35 dispersions showed less color change than mWPCDX100 test samples; therefore, the greater dextran concentrations may have caused diffusion limitations, blocking potential reaction sites, and thus preventing excessive color development (Kato, 2002).

In a previous study by Clare et al. (2005), the lightness $\left(\mathrm{L}^{*}\right)$ of heat-treated milk decreased over time and with prolonged heat treatment, whereas redness, associated with a positive $\mathrm{a}^{*}$ value, was increased. Herein, we report similar trends based on the $\mathrm{L}^{*}$ data obtained (Table 3). Notably, the $a^{*}$ value of heated $m W P C$ was positive, reflecting red hues, whereas mWPC-dextran test samples were negative or greenish. The control (i.e., nonheated $\mathrm{mWPC}$ ) also exhibited a negative $\mathrm{a}^{*}$ reading before complexing with dextran. It is possible that conjugation of $\mathrm{mWPC}$ with dextran reagents, forming mWPC-DX35 and mWPC-DX100 complexes versus lactosylation of $\beta$-LG in heated $\mathrm{mWPC}$ may explain these differences. Furthermore, yellowness, a color associated

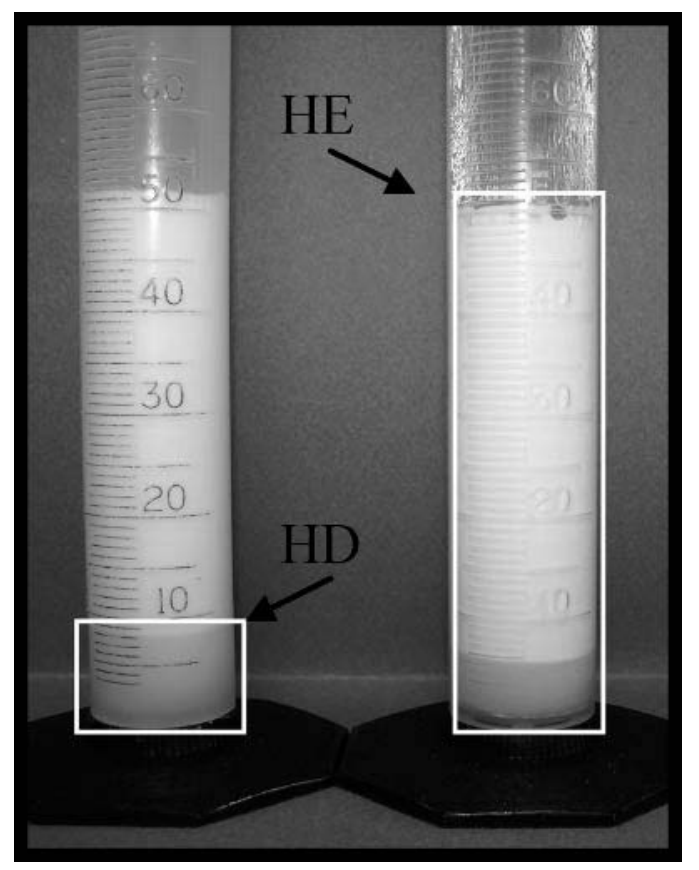

Figure 1. Total height of each emulsion (HE) and the height of the droplet depleted layer (HD). with positive $b^{*}$ values, increased with decreasing $L^{*}$ values. Visual examination of these samples correlated with measured data in that nonheated $\mathrm{mWPC}$ showed little or no yellow coloration, whereas heated mWPC samples exhibited a deep yellow tint. Nasirpour et al. (2006) suggested that yellow color formation may be used as an indicator of nonenzymatic browning.

\section{Ionization Mass Spectrometry}

Leonil et al. (1997) identified lysine residues in $\beta$-LG at positions 47 and 60 as potential sites for carbohydrate attachment during heat processing of milk. In the present experiments, chromatograms from ionization mass spectrometry established that 8.5 and $21.4 \%$ of reactive lysines ( $\beta-\mathrm{LG}$ ) in $\mathrm{mWPC}$ and cWPC dispersions, respectively, were lactosylated as a result of the given processing conditions (Figure 2). The greater incidence of lactosylation observed in cWPC samples is likely a result of the more neutral $\mathrm{pH}$ conditions, which promote increased Maillard reactivity during pasteurization and spray drying. Moreover, additional heat treatment of $\mathrm{mWPC}$ showed an even greater degree of lactosylation (30\%) attributed to further conjugation between lactose and reactive whey protein binding sites. The results observed for the mWPC dispersions were slightly less than those reported by Leonil et al. (1997) after heat treatment, which might be expected considering that their experiments were performed at a more neutral $\mathrm{pH}$ of 6.8 . An attempt was made to assess the degree of glycosylation in mWPC-DX35 and mWPC-DX100 conjugates; however, because of size restrictions of the carbohydrate, this particular method was not applicable.

Table 3. Color measurement of dry powdered modified whey protein concentrate (mWPC) and mWPC-dextran (DX) glyconjugates

\begin{tabular}{lccc}
\hline & \multicolumn{3}{c}{ Color parameter $^{1}$} \\
\cline { 2 - 4 } Sample & $\mathrm{L}^{*}$ & $\mathrm{a}^{*}$ & $\mathrm{~b}^{*}$ \\
\hline mWPC nonheated & $97.92^{\mathrm{a}}$ & $-0.74^{\mathrm{c}}$ & $7.19^{\mathrm{d}}$ \\
mWPC heated & $88.72^{\mathrm{d}}$ & $0.51^{\mathrm{a}}$ & $18.59^{\mathrm{a}}$ \\
mWPC-DX35 heated & $96.03^{\mathrm{b}}$ & $-0.55^{\mathrm{bc}}$ & $11.86^{\mathrm{c}}$ \\
mWPC-DX100 heated & $93.70^{\mathrm{c}}$ & $-0.42^{\mathrm{b}}$ & $14.71^{\mathrm{b}}$ \\
\hline
\end{tabular}

${ }^{\mathrm{a}-\mathrm{d}}$ Means within a column with different superscripts differ $(P<$ $0.05)$.

${ }^{1} \mathrm{~L}^{*}:$ white $=100$, black $=0 ; \mathrm{a}^{*}:$ positive values $=$ red, negative values $=$ green $; b^{*}$ : positive values $=$ yellow, negative values $=$ blue. 


\section{OPA Assay}

Ultimately, the degree of glycosylation is affected by several factors, including the amino acid composition of the protein constituent, the number of accessible amino groups available for complex formation, and the molar ratio of protein to polysaccharide (Jiménez-Castaño et al., 2007). In these experiments, covalent coupling of mWPC to dextran was quantified based on OPA assay measurements, resulting in a decreased concentration of reactive amino sites. Initially, OPA measurements were made to determine the appropriate ratio of protein to carbohydrate necessary to achieve optimal conjugation between mWPC and DX100. With this assay, the greatest loss of soluble reactive amino groups was seen with heated mWPC samples, prepared at a ratio of 2:1 (protein:carbohydrate) compared with those mixed at 3:1 proportions (data not shown). Therefore, this formulation was used for subsequent experiments.

Heated and nonheated samples were prepared in the presence and absence of dextran (2:1 ratio), and the nonheated mWPC fraction was used to establish the baseline. The decreased absorbance readings at $A_{340 \mathrm{~nm}}$ reflected the formation of glycoconjugates, and the de- gree of conjugation appeared to be in agreement with those trends seen with colorimetry. In other words, the greatest loss of free amino groups was observed in the following order: $\mathrm{mWPC}$ heated sample $>\mathrm{mWPC}-$ DX100 > mWPC-DX35 > mWPC nonheated (Table 4). Significant differences were seen among all samples after normalization based on the protein content $(P$ $<0.05)$. Also, these readings likely indicate proteinprotein crosslinking reactions, to some degree, and competition reactions between lactose (naturally occurring in the mWPC powder) versus dextran for reactive protein binding sites. Testing was also performed on mixtures of the mWPC ingredient and dextran before heat treatment to verify that the presence of polysaccharide did not affect OPA results. In this case, no significant differences between the various test samples were observed $(P>0.05$; data not shown).

Previously, Jiménez-Castaño et al. (2007) reported that the decrease in free amino groups, as measured using a trinitrobenzesulfonic acid (TNBS) assay after dry heat treatment of BSA with dextran, was greater than that detected by direct measurement of blocked lysine residues. Such findings were attributed to separate protein-protein interactions or alternative protein-

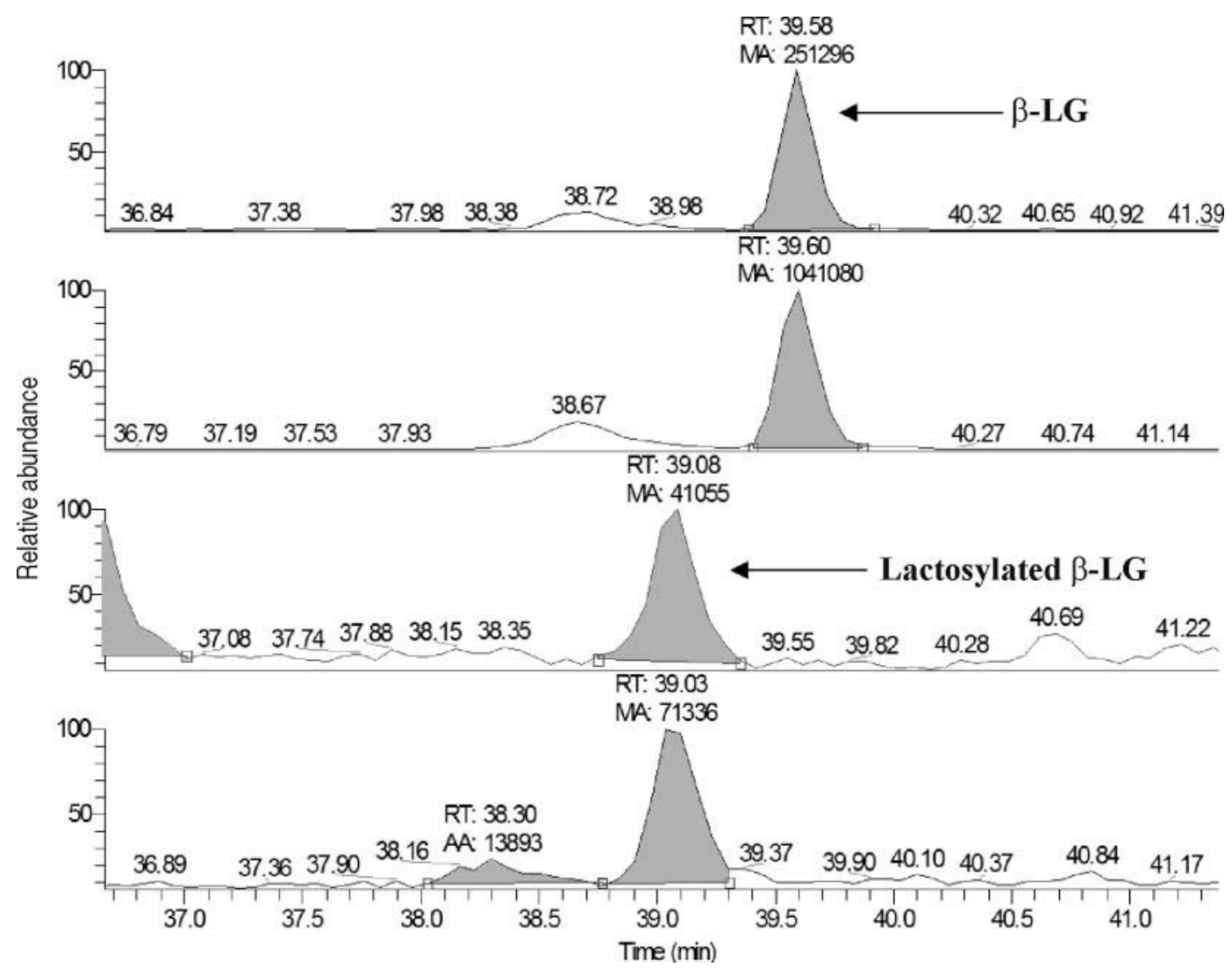

Figure 2. Ionization mass spectrometry chromatography data, in duplicate, illustrating $\beta$-LG peaks from nonheated modified whey protein concentrate (mWPC) samples and lactosylated $\beta$-LG from heated mWPC samples. 
Table 4. Measurement of reactive amino groups in modified whey protein concentrate (mWPC), mWPC-dextran (DX)35, and mWPCDX100 dispersions using o-phthaldialdehyde assay methods

\begin{tabular}{lc}
\hline Sample $^{1}$ & $\mu M / \mathrm{mg}$ of protein \\
\hline mWPC nonheated & $298^{\mathrm{a}}$ \\
mWPC-DX35 heated & $272^{\mathrm{b}}$ \\
mWPC-DX100 heated & $206^{\mathrm{c}}$ \\
mWPC heated & $194^{\mathrm{d}}$ \\
\hline
\end{tabular}

${ }^{\mathrm{a}-\mathrm{d}}$ Means with different superscripts differ $(P<0.05)$.

${ }^{1}$ Reconstituted samples of nonheated $\mathrm{mWPC}$ and heated mWPC $( \pm$ dextran) dispersions, prepared at a 2:1 ratio of protein:carbohydrate.

carbohydrate reactions that were independent of the formation of Amadori products. Similarly, the OPA data reported, herein, may reflect analogous trends.

\section{SDS-PAGE}

Sodium dodecyl sulfate-PAGE results evidenced covalent coupling of mWPC to dextran under dry heating at $100^{\circ} \mathrm{C}$ for $2 \mathrm{~h}$ based on Coomassie (Figure 3A) and glyco-protein (Figure 3B) staining of the gels. As seen in Figure 3A, the banding patterns of dry heated mWPC (lane 4), mWPC-DX35 (lane 5), and mWPCDX100 (lane 6) samples revealed darker staining and more diffuse aggregate bands. The molecular weight of monomeric $\beta-\mathrm{LG}$ and $\alpha-\mathrm{LA}$ appeared slightly increased (Figure 3A and 3B, lane 4), which may be attributed to the high degree of lactosylation that occurred upon heating $\mathrm{mWPC}$ powders. Also, the range of larger end products was broadened upon coupling mWPC to DX100 compared with DX35, a pattern especially notable in gels stained for carbohydrate (Figure 3B). A similar observation was made by Akhtar and Dickinson (2003) using whey protein and dextran reagents.

In Figure 3B, the glyco-pattern of $\mathrm{mWPC}, \mathrm{mWPC}-$ DX35, and mWPC-DX100 samples exhibited a wide carbohydrate staining region. The heated $\mathrm{mWPC}$ and mWPC-DX35 end products spanned the 35 to $210 \mathrm{kDa}$ range, where the mWPC-DX100 test fraction showed evidence of higher molecular weight glycoconjugates $(>210 \mathrm{kDa})$. In early work, Antonini et al. (1964) reported acid hydrolysis of native dextran; therefore, hydrolytic products of dextran may also participate in forming this array of glycoproteins with a varying size distribution. A control dextran sample, both heated and nonheated, was electrophoresed and stained for carbohydrate, and there was no evidence of migration into the gel under these experimental conditions (data not shown).

The glyco-stained $\beta$-LG band was visualized at $\sim 23$ $\mathrm{kDa}$ compared with the nonreacted monomer subunit seen at $\sim 17 \mathrm{kDa}$ with the Coomassie reagent. Overall, newly formed bands were detected with both the carbohydrate-specific reagent and colloidal Coomassie blue, a protein binding dye. Boratynski and Roy (1998) also found that BSA-dextran thermal conjugates migrated as high molecular weight diffuse bands, spanning a range from 75 to $200 \mathrm{kDa}$. Sodium dodecyl sulfatePAGE techniques, coupled with independent staining for both protein and carbohydrate components, have been used to verify covalent linkages between proteincarbohydrate materials in other protein systems as well (Kato et al., 1992; Shu et al., 1996; Akhtar and Dickinson, 2003).

The cWPC sample also exhibited distinct glycoprotein bands at greater molecular weight positions (Figure $3 \mathrm{~B}$, lane 3 ), presumably caused by lactosylation of other whey proteins such as BSA and immunoglobulins during thermal processing and spray drying. Notably, the cWPC ingredient was manufactured at neutral $\mathrm{pH}$ values of 6 to 6.5 , which afford more suitable reaction conditions for the production of Maillard reaction end products (Nursten, 2005).

There remains the possibility that some degree of protein-protein crosslinking may have occurred in these test fractions under the given reaction conditions. Mohammed et al. (2000) described changes in the isoelectric point, solubility, and the degree of browning upon heating several protein reactants, including whey isolates and $\beta$-LG, to 105 to $145^{\circ} \mathrm{C}$ at 3 levels of relative humidity. Such changes were attributed, in part, to the formation of protein crosslinks, whereas darker color formation in the milk powders was associated with high lactose content.

\section{Steady Shear Rheological Analysis}

Rheological analyses of the conjugated and nonconjugated mWPC-lactose or dextran samples were used to elucidate the effects of varying carbohydrate size on the viscosity of the system. Initially, it was hypothesized that covalent linkage of a large polysaccharide to $\mathrm{mWPC}$ would increase the intrinsic viscosity or hydrodynamic radius of the particles, thereby increasing the apparent viscosity. Before heating, mWPC samples containing dextran (2:1 ratio) exhibited an apparent viscosity that was 3.4 times greater than the mWPC dispersion at a shear rate of $50 \mathrm{~s}^{-1}$ (Figure 4A).

However, after heating, mWPC-DX35 and mWPCDX100 samples showed no further increase in apparent viscosity, whereas mWPC dispersions (containing lactose) exhibited a 3 -fold increase with respect to these values (Figure 4B). Possibly, enhanced protein aggregation occurred in the mWPC-dextran samples (Figure $3 \mathrm{~A}$ ), leading to segregative phase separation, creating a protein-rich phase surrounded by a carbohydraterich phase, which in turn diminished protein-protein 
A)

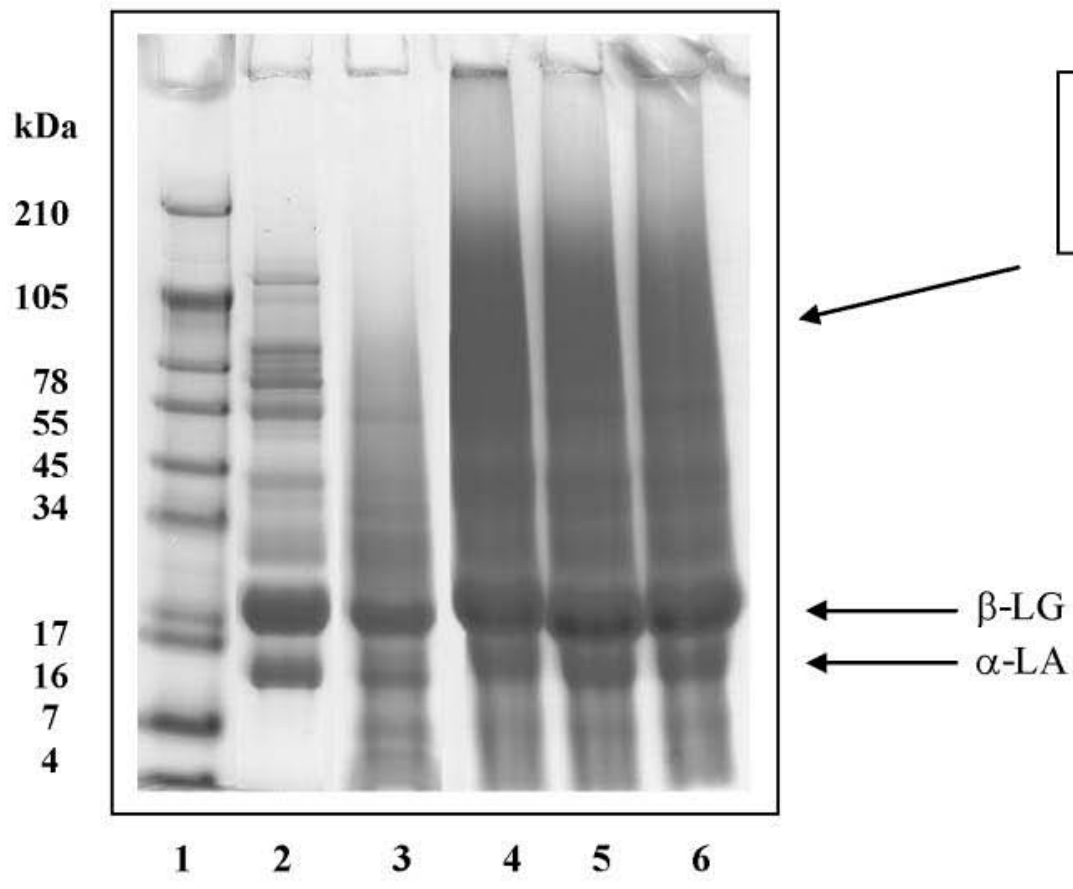

Smearing pattern

indicative of

aggregation and

glyco-conjugation

B)

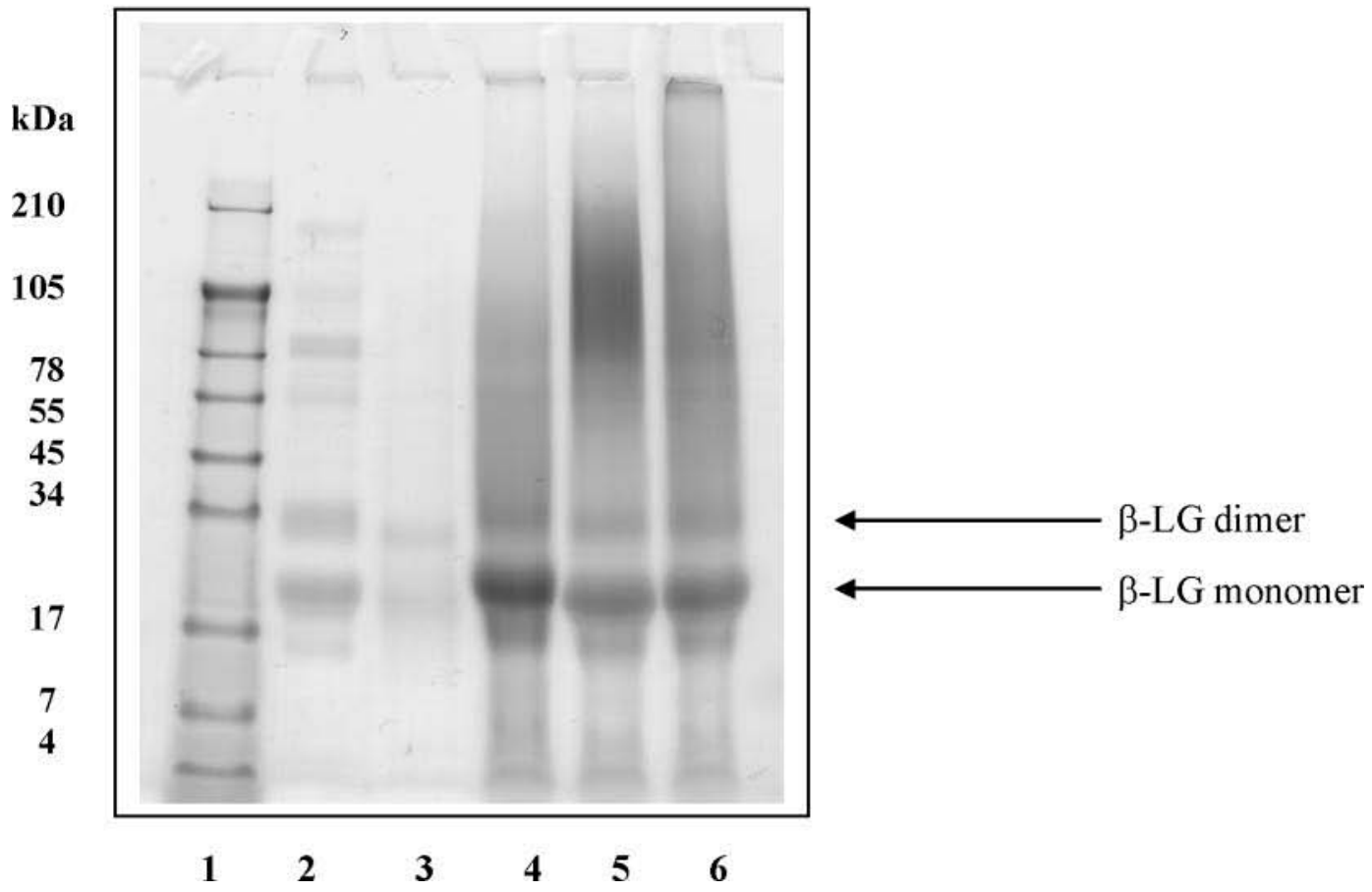

Figure 3. A) SDS-PAGE banding pattern of whey protein and whey protein-carbohydrate conjugates. Lane $1=$ marker protein; lane $2=$ commercial whey protein concentrate $(\mathrm{cWPC})$; lane $3=$ modified whey protein concentrate $(\mathrm{mWPC})$; lane $=$ heated $\mathrm{mWPC}$; lane $5=$ heated mWPC-dextran (DX) 35; lane $6=$ heated mWPC-DX100. Samples in lanes 4, 5, and 6 were heat treated $\left(100^{\circ} \mathrm{C}, 2 \mathrm{~h}\right)$ under dry conditions. All samples were initially prepared at $\mathrm{pH} 3.5$, before electrophoresis, except for cWPC, which was prepared at pH 6.6. B) SDS-PAGE glycoprotein staining pattern of whey protein and whey protein-dextran test samples as loaded in the same order. 
interactions and entanglements (Tuinier et al., 2000). Furthermore, at high temperatures, lactose can be converted into lactulose by rearrangement of aldose structures to ketose conformations. In one study, Matsuda et al. (1991) found that heating $\beta-L G$ in the presence of lactulose resulted in a high degree of protein polymerization. In a similar manner, polymer formation may have occurred in mWPC dispersions, containing both $\beta$-LG and lactose, via an analogous mechanism. In turn, addition of dextran into mWPC protein solutions might interfere with such reactions.

\section{Small Amplitude Oscillatory Shear}

Viscoelastic data of the newly formed mWPC-lactose/dextran glycoconjugates showed similar trends. All samples displayed formation of a viscous semisolid, indicated by $\mathrm{G}^{\prime}$ dominating $\mathrm{G}^{\prime \prime}$, as the frequency was increased over 3 orders of magnitude. Test mWPC-dextran samples, before heat treatment, exhibited a greater degree of gel rigidity compared with $\mathrm{mWPC}$ dispersions as indicated by the higher shear modulus (Figure 5A). Possibly, electrostatic interactions played a primary role in these solution chemistries given that the gel strength $\left(\mathrm{G}^{\prime}\right)$ of mWPC-DX35 fractions was slightly greater than those values measured for mWPC-DX100 protein solutions. Again, the molar concentration of dextran was greater in mWPC-DX35 dispersions, influencing the overall electrostatic potential of the system.

After heating, gel rigidity increased among all sample types, although the most significant change was noted in mWPC dispersions containing only lactose (Figure $5 \mathrm{~B}$ ), where the darkest color formation and greatest loss of reactive amino groups occurred (Tables 2 and $3)$. At protein concentrations of $7 \%$ (wt/vol), all dispersions were homogeneous; that is, they did not phase separate upon visual inspection. Generally speaking, the gel strength was increased in all thermally processed samples, suggesting that covalent bond formation between protein-carbohydrate moieties might play a more significant role than electrostatic factors with respect to affecting gel strength.

\section{Emulsion Stability}

Creaming index determinations were made for all emulsified test samples after storage for 1 wk (Figure 6). Particle size analyses revealed that the average modal diameter of heated and nonheated mWPC dispersions measured approximately $3.6 \mu \mathrm{m}$, whereas the size detected for the commercial WPC sample was approximately $2.5 \mu \mathrm{m}$ compared with 4.5 and $4.9 \mu \mathrm{m}$ for $\mathrm{mWPC}-\mathrm{DX} 35$ and $\mathrm{mWPC}-\mathrm{DX} 100$, respectively.
These values approached $1 \mu \mathrm{m}$, previously designated as an ideal size for the stabilization of emulsions based on hydrodynamic and interparticle forces as well as Brownian motion (Genovese et al., 2007). The creaming indexes were significantly different $(P<0.05)$, and each test fraction exhibited a clear serum layer indicative of phase separation of the emulsion.

The greatest stabilization occurred in heated $\mathrm{mWPC}$ DX35 samples, which showed the least color change and decreased glycosylation compared with mWPC-DX100 dispersions. Previously, Dunlap and Cote (2005) theorized that whey protein-dextran conjugates exhibiting a molecular weight greater than $100 \mathrm{kDa}$ may prevent saturation of the protein around the oil droplet surface, thereby limiting stability. Akhtar and Dickinson (2007) found similar trends using whey protein isolates and maltodextrin, in which whey-maltodextrin $(280 \mathrm{kDa})$ conjugates were less stable than those prepared with a lower molecular weight maltodextrin $(8.7 \mathrm{kDa})$. In a separate report, Akhtar and Dickinson (2003) proposed that the enhanced emulsifying properties of WPI-dextran complexes might actually be attributable to steric stabilization caused by the bulky hydrophilic polysaccharide.

Overall, mWPC dispersions showed greatly improved emulsion stability compared with equivalently prepared cWPC samples. Typically, when whey protein solutions are heated, denaturation occurs with increased hydrophobicity (Tanford, 1973). Voutsinas et al. (1983) observed a positive correlation between hydrophobicity and enhanced emulsifying properties; therefore, this improvement may be explained by the fact that the mWPC ingredient is a heated product compared with cWPC powders, which are not thermally processed to the same degree. Protein solutions prepared with mWPC-dextran samples exhibited a creaming index percentage that was 2 to 3 times less than that of $\mathrm{mWPC}$ or cWPC dispersions, reflecting enhanced emulsion stability. All test samples were normalized for equivalent protein content.

\section{Scanning Electron Microscopy}

Scanning electron micrographs of mWPC and mWPC-DX100 (2:1 ratio) samples, were taken at $2,500 \times$ and $15,000 \times$ magnifications. At $2,500 \times$, surface imagery of mWPC-DX100 dispersions showed a coarse, granular structure with small pockets (Figure $7 \mathrm{~B})$, whereas at $15,000 \times$ (Figure 7D), a highly porous matrix was observed. Conversely, these features were not so apparent in mWPC samples (Figure 7A and C). The glutaraldehyde and formaldehyde fixatives used to crosslink constituent whey proteins enabled 

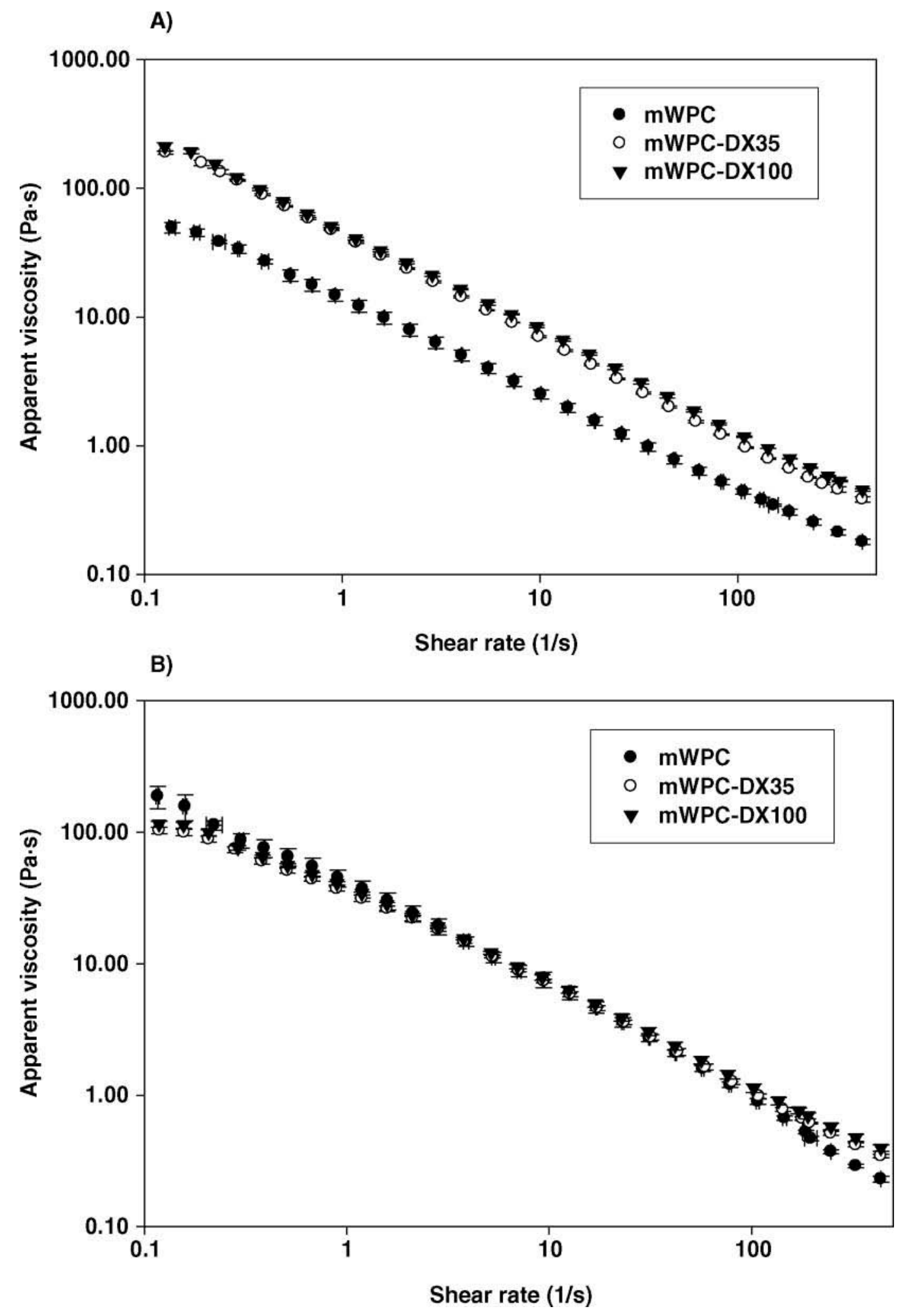

Figure 4. A) Apparent viscosity of reconstituted nonheated modified whey protein concentrate (mWPC; $7 \%$ protein, wt/vol) with or without dextran (DX) and prepared at a 2:1 ratio, over the shear rate range from 0.1 to $500 \mathrm{~s}^{-1}$ at $25^{\circ} \mathrm{C}$. Error bars represent 1 standard deviation from the mean; B) apparent viscosity of reconstituted heated $\left(100^{\circ} \mathrm{C}, 2 \mathrm{~h}\right) \mathrm{mWPC}(7 \%$ protein, wt/vol) with or without DX and prepared at a $2: 1$ ratio, over the shear rate range of 0.1 to $500 \mathrm{~s}^{-1}$ at $25^{\circ} \mathrm{C}$. Error bars represent 1 standard deviation from the mean. 

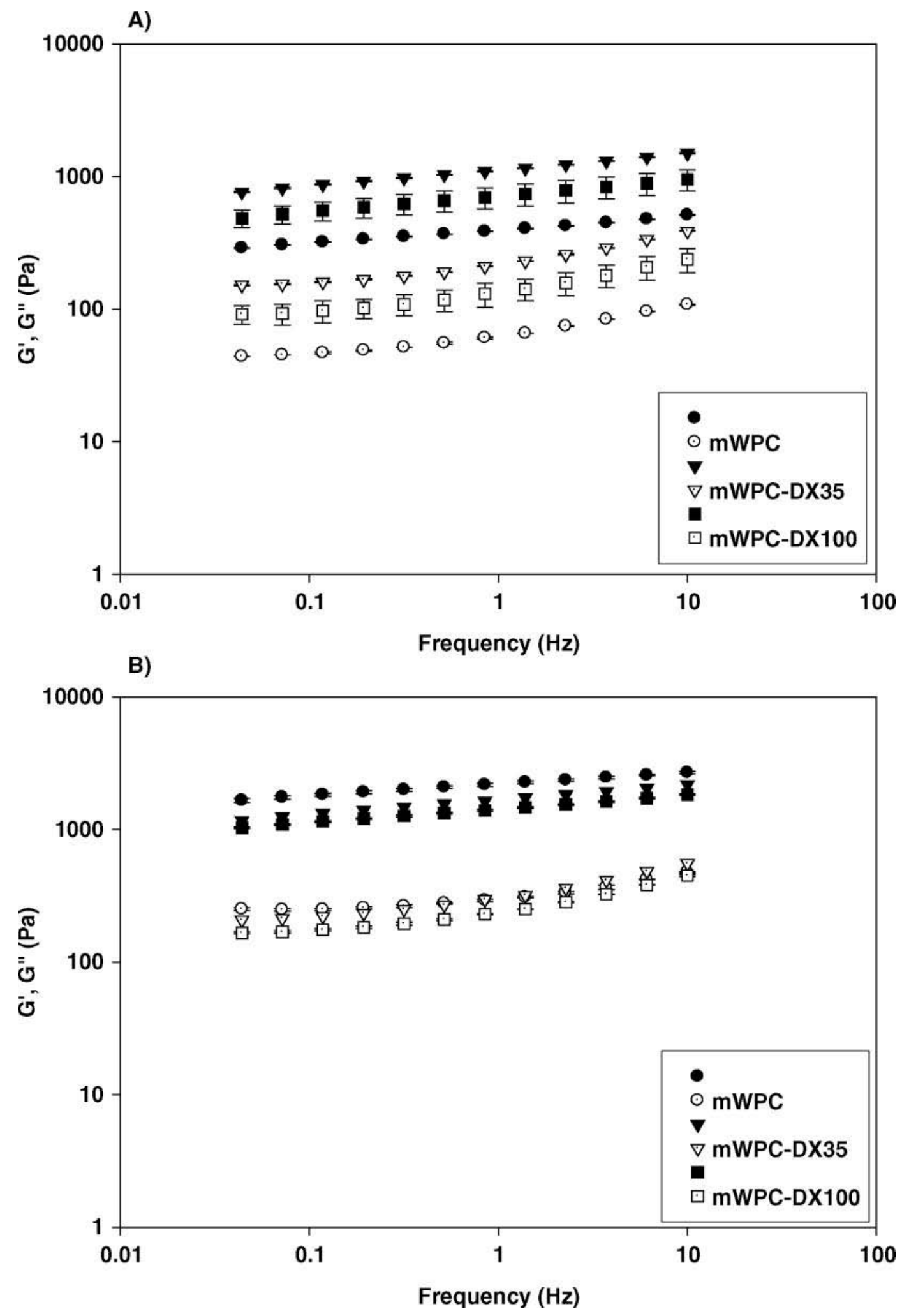

Figure 5. A) Small amplitude oscillatory shear data for reconstituted nonheated modified whey protein concentrate (mWPC; $7 \%$ protein, wt/vol) with or without dextran (DX) and prepared at a 2:1 ratio. Closed symbols indicate $\mathrm{G}^{\prime}$ values and open symbols indicate $\mathrm{G}^{\prime \prime}$ values. Error bars represent 1 standard deviation from the mean; B) small amplitude oscillatory shear data for reconstituted $\mathrm{mWPC}$ (7\%, wt/vol) with or without DX and prepared at a $2: 1$ ratio, after dry heat treatment at $100^{\circ} \mathrm{C}$ for $2 \mathrm{~h}$. Closed symbols indicate $\mathrm{G}^{\prime}$ values and open symbols indicate $\mathrm{G}^{\prime \prime}$ values. Error bars represent 1 standard deviation from the mean. 
their imaging; however, these reagents were unable to fix carbohydrate materials (Visscher and Argentieri, 1987). Therefore, the pockets or gaps may be indicative of the carbohydrate content in the network of mWPCdextran samples, minimizing protein-protein interactions (Dickinson and Chen, 1999).

\section{Water-Holding Capacity}

Additional thermal processing of mWPC dispersions appeared to decrease their capacity to hold water in the following sequence: nonheated $\mathrm{mWPC}>\mathrm{mWPC}$ DX100 > mWPC-DX35 > mWPC-lactose (Figure 8). All values were significantly different $(P<0.05)$, and each sample exhibited a pellet after low speed centrifugation, attributed to the inability to retain water. Although the water-holding capacity was somewhat diminished after thermal treatment, the powders still held nearly 6 times their weight of water.

\section{CONCLUSIONS}

Proteins are highly suited for modification using thermal treatment or carbohydrate complexing reactions achieved by nonchemical means such as the Maillard reaction. Notably, the degree of lactosylation with respect to $\alpha$-LA, $\beta$-LG, and other whey proteins was less in mWPC dispersions compared with cWPC ingredients; therefore, potentially increasing the number of reactive sites that remain available for carbohydrate attachment. There are limited reports regarding Maillard reactions at low $\mathrm{pH}$; however, in one study, Dattatreya and Rankin (2006) described Maillard activity in spray dried sweet whey powder over a $\mathrm{pH}$ range of 4.0 to 6.3. The concentrations of hydroxylmethyl furfural were greater in samples of low $\mathrm{pH}$ "confirming that the 3-deoxyosone pathway was involved."

These data established that lactosylation of $\beta-\mathrm{LG}$ occurred at low $\mathrm{pH}$, given the MS profile. Presumably, glycosylation linkages would occur between mWPC fractions and dextran via a similar mechanism, albeit at a lower level based on competition between lactose and dextran for reactive protein binding sites.

Moreover, steric hindrance may interfere with glycosylation especially in mWPC dispersions containing DX100. Conjugate formation was evidenced by a reduction in reactive amino groups, darkened color formation, SDS-PAGE protein and glycoprotein staining patterns, rheological changes, and scanning electron microscopy. Although some degree of protein-protein crosslinking likely occurred, the final functional parameters of the resultant end products appeared to be affected by the specific carbohydrate reagent used for making glycoconjugates.

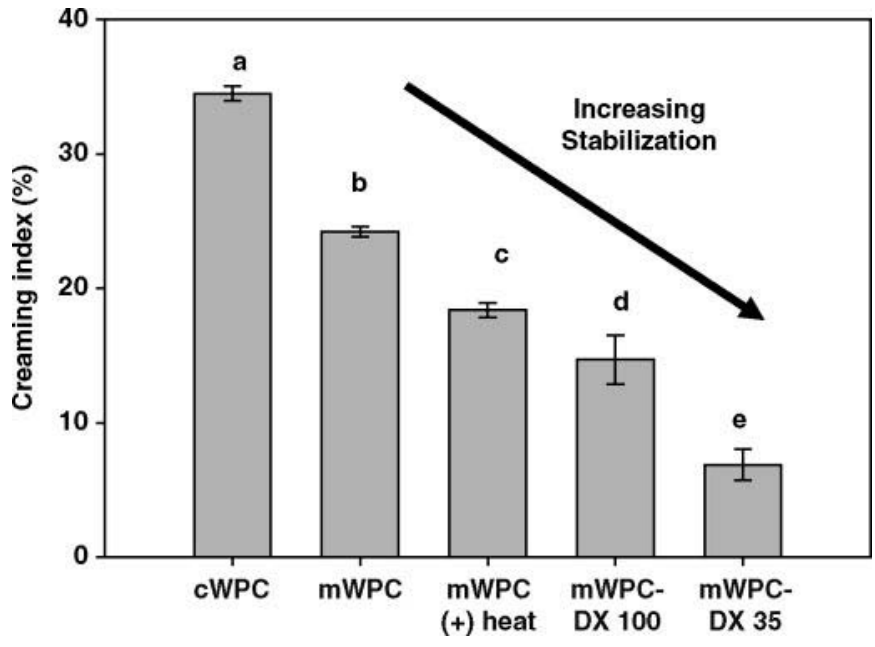

Figure 6. Plot of creaming index values for $5 \mathrm{mg} / \mathrm{mL}$ protein solutions of commercial whey protein concentrate (cWPC), modified whey protein concentrate (mWPC), and heated mWPC, mWPC-dextran (DX)100, mWPC-DX35 dispersions, prepared at a 2:1 ratio, measured after 1 wk at ambient temperature. Error bars represent 1 standard deviation from the mean. All samples were prepared at $\mathrm{pH} 3.5$ except for cWPC, which was prepared at $\mathrm{pH}$ 6.6. ${ }^{\mathrm{a}-\mathrm{e}}$ Different letters indicate significant differences $(P<0.05)$.

A greater viscosity was observed in mWPC ingredients after heating in the presence of lactose; however, no increase was seen in thermally processed wheydextran test samples. Gel rigidity was enhanced to the greatest degree using mWPC test samples, containing lactose, after a second heat treatment. Potentially, such findings might benefit manufacturers of whey protein concentrates because improved functionality was achieved based on the presence of a naturally occurring simple sugar (lactose) that was already present in the product.

The greatest benefit of conjugating higher molecular weight polysaccharides such as dextran with whey protein materials appeared to be correlated with its capacity to stabilize emulsions. Emulsion stability was greatest in thermally treated mWPC-dextran samples although the degree of conjugation and extent of color change was lower compared with $\mathrm{mWPC}$ dispersions per se. Ultimately, the performance characteristics of mWPC proteins may be enhanced as a result of carbohydrate attachment using simple sugars or complex carbohydrates. With these approaches, mWPC-based glycoproteins may offer new versatility as a potential new food ingredient.

\section{ACKNOWLEDGMENTS}

The authors recognize Grande Cheese Inc. (Lomira, WI) for providing the mWPC and ULTRA 8000 


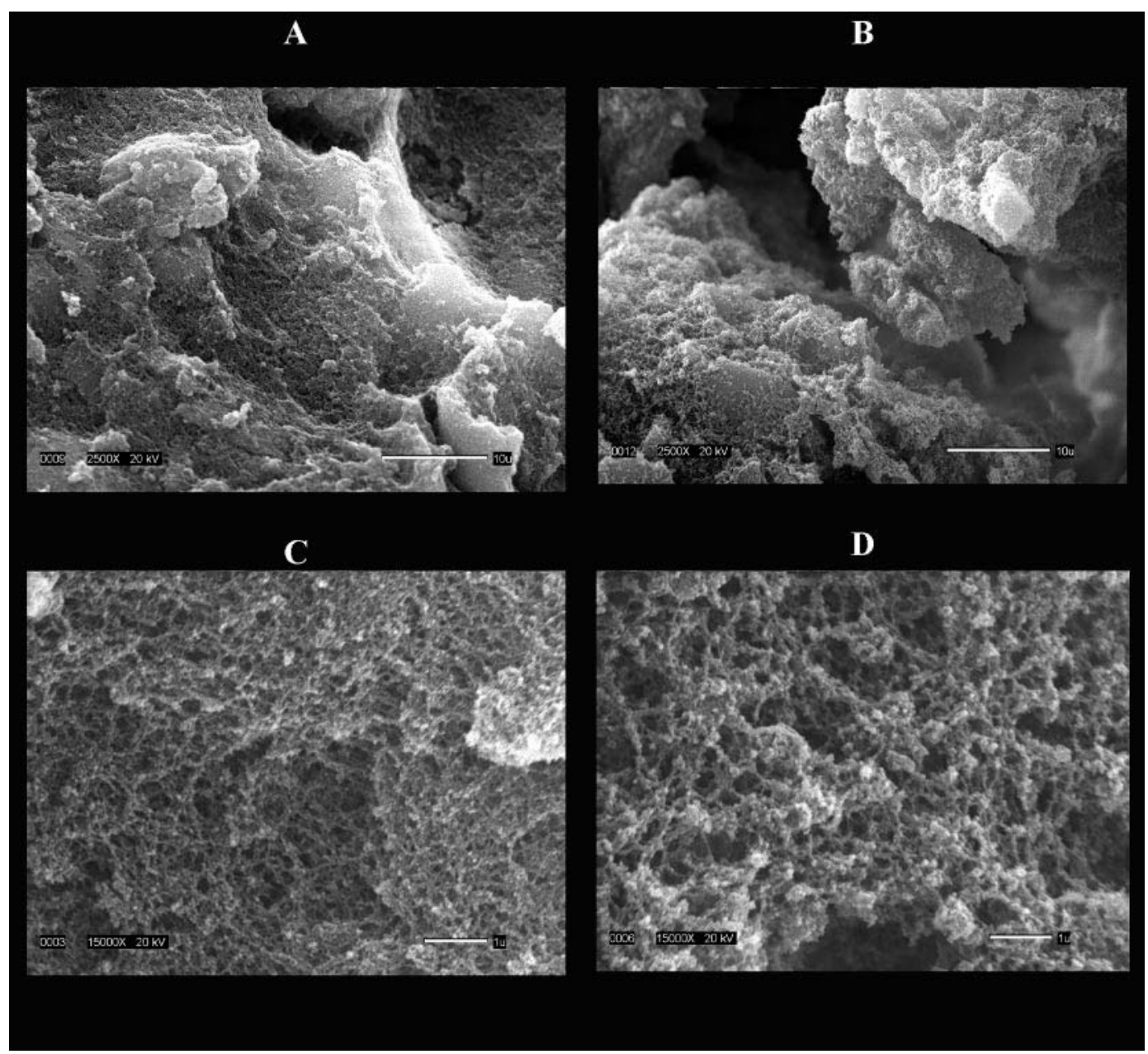

Figure 7. Scanning electron micrographs of modified whey protein concentrate (mWPC) and mWPC-dextran (DX) samples (5.6\% protein,

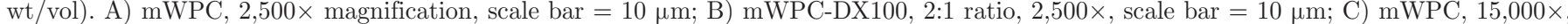
scale bar $=1 \mu \mathrm{m}$; and (D) mWPC-DX100, 2:1 ratio, $15,000 \times$, scale bar $=1 \mu \mathrm{m}$.

(cWPC) ingredients used in these studies. Also, we are grateful to Dave Taylor and Tom Helm of Grande Cheese Inc. for astute conversations regarding the manufacturing of mWPC and cWPC protein products. A special acknowledgment is extended to Nigel Deighton and the NC State University Proteomics Center for evaluating lactosylation of $\beta$-LG with ionization mass spectrometry, and Sharon Ramsey for her invaluable assistance with rheological measurements. Many thanks are extended to George Catignani, who participated in several discussions regarding the Maillard reaction, and last, we recognize the contributions of Valerie Knowlton of the Center for Electron Microscopy, who provided expert assistance with respect to scanning electron microscopy protocols. With gratitude, we would like to acknowledge the USDA-NRI granting agency for funding of this project.

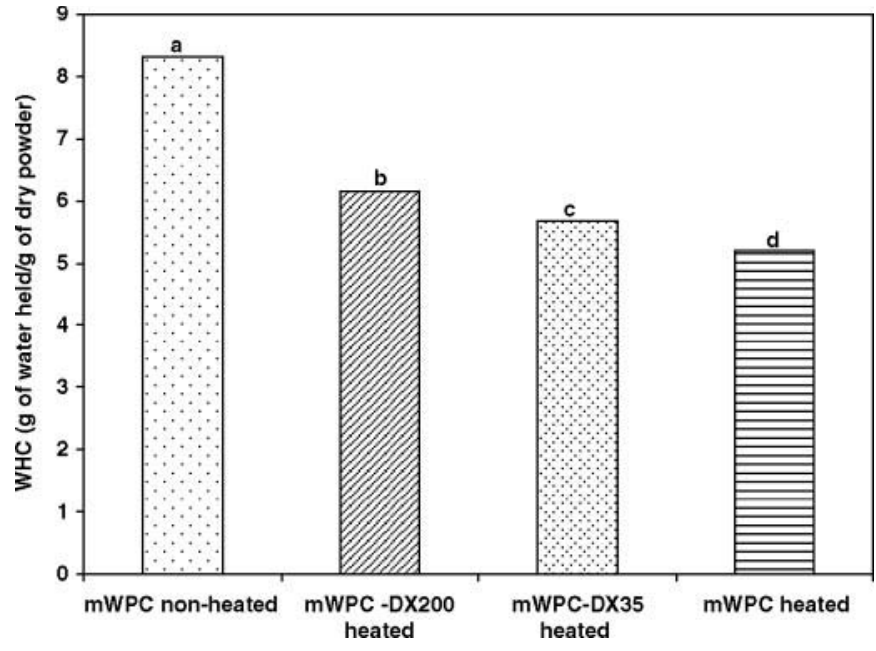

Figure 8. Changes in the water-holding capacity of nonheated and heated modified whey protein concentrate (mWPC; $5.6 \%$ protein) prepared in the presence and absence of dextran (DX, 2:1 ratio) at $\mathrm{pH} 3.5$. ${ }^{\mathrm{a}-\mathrm{d}}$ Different letters indicate significant differences $(P<0.05)$. 


\section{REFERENCES}

Akhtar, M., and E. Dickinson. 2003. Emulsifying properties of whey protein-dextran conjugates at low $\mathrm{pH}$ and different salt concentrations. Colloids Surf. B Biointerfaces 31:125-132.

Akhtar, M., and E. Dickinson. 2007. Whey protein-maltodextrin conjugates as emulsifying agents: An alternative to gum arabic. Food Hydrocolloids 21:607-616.

Antonini, E., L. Bellelli, M. L. Bonacci, M. R. Bruzzesi, A. Caputo, E. Chiancone, and A. Rossi-Fanelli. 1964. Studies on dextran and dextran derivatives. II. Acid hydrolysis of native dextran. Biopolymers 2:35-42.

Balagtas, J. V., F. M. Hutchinson, J. M. Krochta, and D. A. Sumner 2003. Anticipating market effects of new uses for whey and evaluating returns to research and development. J. Dairy Sci. $86: 1662-1672$

Boratynski, J., and R. Roy. 1998. High temperature conjugation of proteins with carbohydrates. Glycoconj. J. 15:131-138.

Church, F. C., H. E. Swaisgood, D. H. Porter, and G. L. Catignani 1983. Spectrophotometric assay using o-phthaldialdehyde for determination of proteolysis in milk and isolated milk proteins. J. Dairy Sci. 66:1219-1227.

Clare, D. A., W. S. Bang, G. Cartwright, M. A. Drake, P. Coronel, and J. Simunovic. 2005. Comparison of sensory, microbiological, and biochemical parameters of microwave versus indirect UHT fluid skim milk during storage. J. Dairy Sci. 88:4172-4182.

Dattatreya, A., and S. Rankin. 2006. Moderately acidic $\mathrm{pH}$ potentiates browning of sweet whey powder. Int. Dairy J. 16:822-828.

Demetriades, K., and D. J. McClements. 1999. Flocculation of whey protein stabilized emulsions as influenced by dextran sulfate and electrolyte. J. Food Sci. 64:206-210.

DeWit, J. N. 1984. Functional properties of whey proteins in food systems. Neth. Milk Dairy J. 38:71-89.

DeWit, J. N. 1989. Functional properties of whey proteins. Page 285 in Developments in Dairy Chemistry. Vol. 4. Elsevier Applied Science, New York, NY.

Dickinson, E., and J. Chen. 1999. Heat-set whey protein emulsion gels: Role of active and inactive filler particles. J. Dispers. Sci. Technol. 20:197-213.

Dickinson, E., and E. Izgi. 1996. Foam stabilization by proteinpolysaccharide complexes. Colloids Surf. 113:191-201.

Dickinson, E., and M. G. Semenova 1992. Emulsifying behaviour of protein in the presence of polysaccharide under conditions of thermodynamic incompatibility. J. Chem. Soc. Faraday Trans. $88: 849-854$.

Dunlap, C. A., and G. L. Cote. 2005. $\beta$-Lactoglobulin-dextran conjugates: Effect of polysaccharide size on emulsion stability. J. Agric. Food Chem. 53:419-423.

Einhorn-Stoll, U., M. Ulbrich, S. Sever, and H. Kunzek. 2005. Formation of milk protein-pectin conjugates with improved emulsifying properties by controlled dry heating. Food Hydrocolloids 19:329340.

Firebaugh, J. D. 2004. Characterization and application of a derivatized whey ingredient. MS Thesis. NC State University, Raleigh.

Genovese, D. B., J. E. Lozano, and M. A. Rao. 2007. The rheology of colloidal and noncolloidal dispersions. J. Food Sci. 72:R11-R20.

Hudson, H. M., C. R. Daubert, and E. A. Foegeding. 2001. Thermal and $\mathrm{pH}$ stable protein thickening agent and method of making the same. US Patent No.6261624. Assignee: North Carolina State University.

HunterLab. 1996. Hunter lab color scale. Insight on color. Applications Note. 8:1-4. Hunter Laboratories, Reston, VA.

Jiménez-Castaño, L., M. Villameil, and R. Lopez-Fandino. 2007. Glycosylation of individual whey proteins by Maillard reaction using dextran of different molecular mass. Food Hydrocolloids 21:433-443.

Kato, A. 2002. Industrial applications of Maillard-type proteinpolysaccharide conjugates. Food Sci. Technol. Res. 8:193-199.

Kato, A., R. Mifuru, N. Matsudomi, and K. Kobayashi. 1992 Functional casein-polysaccharide conjugates prepared by controlled dry heating. Biosci. Biotechnol. Biochem. 56:567-571.
Kinsella, J. E., D. M. Whitehead, J. Brady, and N. A. Bringe. 1989 Milk proteins: Possible relationships of structure and function. Page 55 in Developments in Dairy Chemistry. Vol. 4. Elsevier Applied Science, New York, NY.

Leonil, J., D. Molle, J. Faubquant, J. L. Maubois, R. J. Pearce, and S. Bouhallab. 1997. Characterization by ionization mass spectrometry of lactosyl $\beta$-lactoglobulin conjugates formed during heat treatment of milk and whey and identification of one lactose-binding site. J. Dairy Sci. 80:2270-2281.

Matsuda, T., Y. Kato, and R. Nakamura. 1991. Lysine loss and polymerization of bovine $\beta$-lactoglobulin by amino carbonyl reaction with lactulose. J. Agric. Food Chem. 39:1201-1204.

Mishra, S., B. Mann, and V. K. Joshi. 2001. Functional improvement of whey protein concentrate on interaction with pectin. Food Hydrocolloids 15:9-15.

Mohammed, Z. H., S. E. Hill, and J. R. Mitchell. 2000. Covalent crosslinking in heated protein systems. J. Food Sci. Food Chem. Toxicol. 65:221-226.

Morr, C. V. 1979. Functionality of whey protein products. N. Z. J. Dairy Sci. Technol. 14:185-194.

Morr, C. V. 1982. Functional properties of milk proteins and their use as food ingredients. Page 375 in Developments in Dairy Chemistry. Vol 1. Proteins. P. F. F ox, ed. Applied Science, New York, NY.

Morr, C. V., and E. Y. W. Ha. 1993. Whey protein concentrates and isolates: Processing and functional properties. Crit. Rev. Food Sci. Nutr. 33:431-476.

Nasirpour, A., J. Scher, M. Linder, and S. Desobry. 2006. Modeling of lactose crystallization and color changes in model infant foods. J. Dairy Sci. 89:2365-2373.

Nielson, B. R., H. Stapelfeldt, and L. Skibsted. 1997. Early prediction of the shelf-life of medium-heat whole milk powders using stepwise multiple regression and principal component analysis. Int. Dairy J. $7: 341-348$

Nursten, H. 2005. The Maillard reaction. Pages 31-32 in Chemistry, Biochemistry, and Implications. Royal Society of Chemistry, London, UK

Oliver, C. M., L. D. Melton, and R. A. Stanley. 2006. Creating proteins with novel functionality via the Maillard reaction: A review. Crit. Rev. Food Sci. Nutr. 46:337-350.

Onwulata, C. I., R. P. Konstance, and P. M. Tomasula. 2004. Minimizing variations in functionality of whey protein concentrates from different sources. J. Dairy Sci. 87:749-756.

Resch, J. J., and C. R. Daubert. 2002. Rheological and physiochemical properties of derivatized whey protein concentrate powders. Int. J. Food Prop. 5:419-434.

Reyes, F. G. R., B. Poocharoen, and R. E. Wrolstad. 1982. Maillard browning reaction of sugar-glycine model systems: Changes in sugar concentration, color and appearance. J. Food Sci. 47:13761377.

Shu, Y. W., S. Sahara, S. Nakamura, and A. Kato. 1996. Effects of the length of polysaccharide chains on the functional properties of the Maillard-type lysozyme-polysaccharide conjugate . J. Agric. Food Chem. 44:2544-2548.

Smith, P. K., R. I. Krohn, G. T. Hermanson, A. K. Mallia, F. H. Gartner, M. D. Provenzano, E. K. Fujimoto, N. M. Goeke, B. J. Olson, and D. C. Klenk. 1985. Measurement of protein using bicinchoninic acid. Anal. Biochem. 150:76-85.

Tanford, C. 1973. The Hydrophobic Effect: Formation of Micelles and Biological Membranes. John Wiley and Sons, New York, NY.

Tuinier, R., J. K. G. Dhont, and C. G. De Kruif. 2000. Depletioninduced phase separation of aggregated whey protein colloids by an exocellular polysaccharide. Langmuir 16:1497-1507.

USDA. 2006. http://www.ams.usda.gov/dairy/mncs/graphs/dy 20060804mWPC_prod.pdf. Accessed January 2007.

Visscher, G. E., and G. J. Argentieri. 1987. Fundamentals of fixation: An introductory overview. EMSA Bull. 17:2.

Voutsinas, L. P., E. Cheung, and S. Nakai. 1983. Relationship of hydrophobicity to emulsifying properties of heat denatured proteins. J. Food Sci. 48:26-32. 